\title{
The Neural Bases of Tinnitus: Lessons from Deafness and Cochlear Implants
}

\author{
${ }^{\circledR}$ Marlies Knipper, ${ }^{1}{ }^{\circledR}$ Pim van Dijk, ${ }^{2,3}$ Holger Schulze, ${ }^{4}$ Birgit Mazurek, ${ }^{5}$ Patrick Krauss, ${ }^{4}{ }^{\circledR}$ Verena Scheper, ${ }^{6,7}$ \\ ${ }^{1}$ Athanasia Warnecke, ${ }^{6,7}$ Winfried Schlee, ${ }^{8}$ Kerstin Schwabe, ${ }^{6,7}$ Wibke Singer, ${ }^{1}$ Christoph Braun, ${ }^{9}$ \\ ${ }^{\circ}$ Paul H. Delano, ${ }^{10}$ Andreas J. Fallgatter, ${ }^{11}$ Ann-Christine Ehlis, ${ }^{11}$ Grant D. Searchfield, ${ }^{12,13}$ \\ Matthias H.J. Munk, ${ }^{11,14}$ David M. Baguley, ${ }^{15,16}$ and Lukas Rüttiger ${ }^{1}$ \\ ${ }^{1}$ University of Tübingen, Department of Otolaryngology, Head and Neck Surgery, Tübingen Hearing Research Center, Molecular Physiology of Hearing, 72076 \\ Tübingen, Germany, ${ }^{2}$ Department of Otorhinolaryngology/Head and Neck Surgery, University of Groningen, University Medical Center Groningen, 9700 AB \\ Groningen, The Netherlands, ${ }^{3}$ Graduate School of Medical Sciences (Research School of Behavioural and Cognitive Neurosciences), University of Groningen, \\ 9700 AB Groningen, The Netherlands, ${ }^{4}$ Experimental Otolaryngology, Neuroscience Laboratory, University Hospital Erlangen, Friedrich-Alexander University \\ Erlangen-Nürnberg, 91054 Erlangen, Germany, ${ }^{5}$ Charité-Universitätsmedizin Berlin, Tinnituszentrum, 10117 Berlin, Germany, ${ }^{6}$ Department of Otorhinolaryngology, \\ Head and Neck Surgery, Hannover Medical School, 30625 Hannover, Germany, ${ }^{7}$ Cluster of Excellence "Hearing4all" of the German Research Foundation, 30625 \\ Hannover, Germany, ${ }^{8}$ Department of Psychiatry and Psychotherapy, University of Regensburg, 93053 Regensburg, Germany, ${ }^{9}$ MEG Center, University Hospital \\ Tübingen, 72076 Tübingen, Germany, ${ }^{10}$ Departments of Otolaryngology and Neuroscience, Faculty of Medicine, University of Chile, 15782 Santiago, Chile, \\ ${ }^{11}$ Department of Psychiatry, University of Tübingen, 72076 Tübingen, Germany, ${ }^{12}$ Eisdell Moore Centre, Audiology Section, University of Auckland, 1546 \\ Auckland, New Zealand, ${ }^{13}$ Brain Research New Zealand, Centre for Brain Research, University of Auckland, 1142 Auckland, New Zealand, ${ }^{14}$ Department of Biology, \\ Technical University Darmstadt, 64287 Darmstadt, Germany, ${ }^{15}$ Hearing Sciences, Division of Clinical Neuroscience, School of Medicine, University of Nottingham, \\ NG15DU Nottingham, United Kingdom, and ${ }^{16}$ NIHR Nottingham Biomedical Research Centre, University of Nottingham, NG72UH Nottingham, United Kingdom
}

Subjective tinnitus is the conscious perception of sound in the absence of any acoustic source. The literature suggests various tinnitus mechanisms, most of which invoke changes in spontaneous firing rates of central auditory neurons resulting from modification of neural gain. Here, we present an alternative model based on evidence that tinnitus is: (1) rare in people who are congenitally deaf, (2) common in people with acquired deafness, and (3) potentially suppressed by active cochlear implants used for hearing restoration. We propose that tinnitus can only develop after fast auditory fiber activity has stimulated the synapse formation between fast-spiking parvalbumin positive $\left(\mathrm{PV}^{+}\right)$interneurons and projecting neurons in the ascending auditory path and coactivated frontostriatal networks after hearing onset. Thereafter, fast auditory fiber activity promotes feedforward and feedback inhibition mediated by $\mathrm{PV}^{+}$ interneuron activity in auditory-specific circuits. This inhibitory network enables enhanced stimulus resolution, attention-driven contrast improvement, and augmentation of auditory responses in central auditory pathways (neural gain) after damage of slow auditory fibers. When fast auditory fiber activity is lost, tonic $\mathrm{PV}^{+}$interneuron activity is diminished, resulting in the prolonged response latencies, sudden hyperexcitability, enhanced cortical synchrony, elevated spontaneous $\gamma$ oscillations, and impaired attention/stress-control that have been described in previous tinnitus models. Moreover, because fast processing is gained through sensory experience, tinnitus would not exist in congenital deafness. Electrical cochlear stimulation may have the potential to reestablish tonic inhibitory networks and thus suppress tinnitus. The proposed framework unites many ideas of tinnitus pathophysiology and may catalyze cooperative efforts to develop tinnitus therapies.

Received June 7, 2019; revised Aug. 5, 2020; accepted Aug. 8, 2020.

M.K. and L.R. this work were supported by German Research Foundation DFG-Kni-316-4-1 and SPP16-08 DFG. P.H. D. was supported by Fondecyt 1161155, CONICYT BASAL FB008, and Proyecto ICM P09-015F. P.v.D., B.M., and H.S. were supported by European Union's Horizon 2020 research and innovation program under the Marie Sklodowska-Curie Grant Agreement 764604 (TIN-ACT). P.v.D., B.M., and W. Schlee were supported by European Union's Horizon 2020 research and innovation program under the Marie Sklodowska-Curie Grant Agreement 722046 (ESIT). D.M.B. was supported by NHR; his views are his own and do not represent those of NHHR nor he UK Department of Health and Care. We thank Jennifer Schulze (Cluster of Excellence "Hearing4all" of the German Research Foundation) for excellent support in designing the schematic sketch. English language services were provided by www.stels-ol.de.

The authors declare no competing financial interests.

Correspondence should be addressed to Marlies Knipper at marlies.knipper@uni-tuebingen.de or Pim van Dijk at p.van.dijk@umcg.nl.

https://doi.org/10.1523/JNEUROSCI.1314-19.2020

Copyright $\odot 2020$ the authors

\section{Introduction}

Chronic, subjective tinnitus, an auditory phantom sensation, affects approximately one-sixth of the general population (Shargorodsky et al., 2010). Tinnitus can be triggered by a variety of causes that may act synergistically (Tyler et al., 2008a; Henry et al., 2014; Moller et al., 2015), but hearing loss is the biggest risk factor for tinnitus (Roberts et al., 2010; Knipper et al., 2013; Lanting et al., 2014; Bauer, 2018). The majority of tinnitus researchers assume that tinnitus is linked to damage or dysfunction in the periphery of the auditory system (Demeester et al., 2007). Because tinnitus can occur without hearing threshold elevation (Roberts et al., 2010; Geven et al., 2011; Langers et al., 2012; Lanting et al., 2014) and normal hearing thresholds rely on 

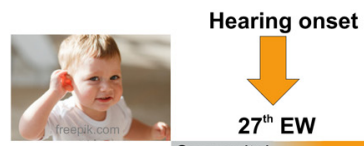

Human
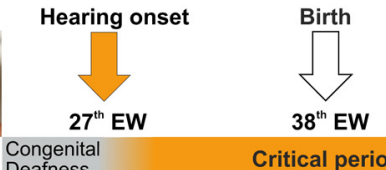

Critical period Acquired deafness

Low Risk of Tinnitus

High Risk of Tinnitus

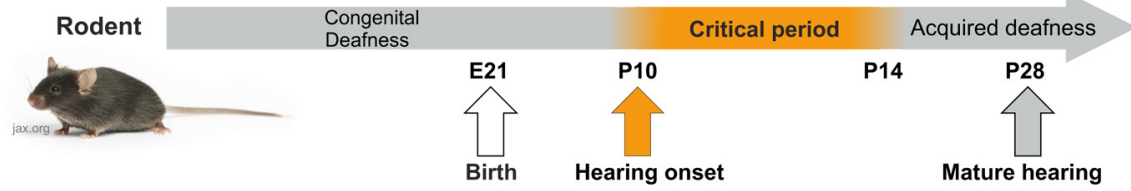

Figure 1. Timing of hearing onset and major maturation steps in the auditory pathway relative to birth. In humans, hearing starts in utero at about embryonic week (EW) 27, followed by a critical period with hearing experience. This critical period spans intrauterine and extrauterine periods up to at least 6-12 months. Adult-like, mature hearing is reached 2-3 years after birth. In rodents, hearing starts after birth (embryonal day 21: E21) at postnatal day 10 (P10) followed by at P10 followed by the critical period until $\sim$ P14. Mature hearing is reached by $\sim P 28$. The risk of tinnitus is high after the critical time period and in acquired deafness.

the proper function of outer hair cells (Dallos, 2008), outer hair cell dysfunction is unlikely to be a primary cause of tinnitus. Instead, deafferentation of inner hair cells by auditory nerve fibers is suggested to be linked to tinnitus in animal models (Müller et al., 2003; Bauer et al., 2007; Roberts et al., 2010; Knipper et al., 2013; Rüttiger et al., 2013; Singer et al., 2013) and in humans (Weisz et al., 2006; Geven et al., 2011; Langers et al., 2012; Boyen et al., 2014; Gilles et al., 2016; Guest et al., 2017; Milloy et al., 2017; Hofmeier et al., 2018). Other risks for tinnitus include anxiety and stress-related disorders (Canlon et al., 2013; Durai and Searchfield, 2016; Mazurek et al., 2017).

From studies on auditory neurons, tinnitus has been linked to hyperexcitability and elevated spontaneous activity in the brain. Such increases in activity are observed, for example, in the cochlear nucleus (Auerbach et al., 2014; Gao et al., 2016), the inferior colliculus (Bauer et al., 2008), the medial geniculate body (Kalappa et al., 2014), and the auditory cortex (AC) (Norena and Farley, 2013; Eggermont and Tass, 2015) after acoustic trauma, ototoxicity, or deafferentation of auditory nerve fibers. There is an ongoing debate about the source of hyperexcitabililty and elevated spontaneous activity, however. Most previous tinnitus literature suggested that tinnitus is the result of homeostatic increases in central neural gain (for review, see Norena, 2011; Schaette and McAlpine, 2011; Schaette and Kempter, 2012; Auerbach et al., 2014; Sedley et al., 2016; Shore et al., 2016; Roberts, 2018; Roberts and Salvi, 2019). In contrast, other studies propose that tinnitus is not related to increased central gain (Zeng, 2013; Möhrle et al., 2019; Sedley, 2019), but instead occurs when auditory input falls short of thresholds for increasing neural gain, so stimulus-evoked responses are diminished in the ascending auditory path (Rüttiger et al., 2013; Singer et al., 2013; Zeng, 2013; Hofmeier et al., 2018; Möhrle et al., 2019). In the present review, we question the previous hypotheses that neural gain is the source of tinnitus, and propose instead that hyperexcitability during tinnitus is the result of a failure to generate central neural gain because of impairment of an inhibitory network that had developed with maturation of fast auditory fibers to enable high stimulus resolution. In this view, a loss of fast auditory fibers would reduce the drive for tonic inhibition in auditoryspecific circuits, resulting in the emergence of hyperactivity that underlies tinnitus. Hence, tinnitus may only develop after fast auditory fibers have stimulated the development of tonic inhibition within these auditory-specific circuits and would not
Mature hearing

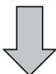

2 years develop in persons with congenital deafness. This hypothesis would explain why congenital deafness is rarely associated with tinnitus, whereas acquired deafness is often associated with tinnitus (Eggermont and Kral, 2016). We moreover suggest that fast auditory fibers that mature with sensory experience improve stimulus resolution through brainderived-neurotrophic factor (BDNF)-dependent synapse formation between fastspiking parvalbumin-positive $\left(\mathrm{PV}^{+}\right)$inhibitory interneuron complex dendritic networks and pyramidal projection neurons in the ascending auditory path, as shown for the AC (Xu et al., 2010). Thereby the representation of specific auditory stimuli can be integrated in distributed frontostriatal networks that control attention-driven amplification processes. Through the activation of this network, precisely timed, stimulus-driven bottom-up feedforward, and top-down feedback activity can accentuate relevant over irrelevant stimuli by contrast amplification, as we discuss in more detail later in this article. The loss of the critical drive that maintains baseline tonic inhibitory $\mathrm{PV}^{+}$network activity may cause an increase in spontaneous firing rates (SFRs) in central auditory circuits and impair input for specific contrast amplification in affected frequency-specific auditory regions, resulting in tinnitus. This view is consistent with various earlier findings that link tinnitus with (1) insufficient gain control, (2) central hyperexcitability, (3) excessive cortical synchrony, elevated $\gamma$ oscillations and corrupted noise-cancellation, (4) increased spontaneous neural activity generated through stochastic resonance, (5) disrupted functional connectivity between auditory-specific and frontostriatal microcircuits, or (6) amplification of a tinnitus precursor through attention or stress. This view is also consistent with previous findings that suggest that tinnitus can be suppressed by cochlear implant (CI) stimulation or by hearing aids (Punte et al., 2013; Knopke et al., 2017). By bringing together the single parts in this review, we trust that new synergies and mutual scientific exchange will help to develop a cure for tinnitus.

\section{Tinnitus occurs with low prevalence in congenital deafness but with high prevalence in acquired deafness}

Rodents are unable to hear when they are born on embryonic day 21, and hearing onset is delayed until postnatal day 10 (P10) (Fig. 1, rodent). This is different from the human fetus, in which hearing starts during embryonic week 27 (Fig. 1, human). After hearing onset, there is a critical period during which hearing experience shapes the acuity and fidelity of hearing (Fig. 1, critical period). In rodents, the critical period extends from P10 to P14 (de Villers-Sidani et al., 2007) and in humans, it likely occurs between the 27 th embryonic week and the sixth to 12 th month after birth (Sharma et al., 2016).

Auditory experience has been suggested as a possible prerequisite for tinnitus because tinnitus has been reported to be absent in congenital deafness (Eggermont and Kral, 2016). Several studies have surveyed the prevalence of tinnitus in hearing-impaired young adults, and tinnitus does not seem to be problematic in younger children (Baguley and McFerran, 2002; Rosing et al., 2016). In responses to direct questioning, reports of tinnitus are higher in moderately or severely hearing-impaired youth than in 
those with profound loss. In addition, those with acquired loss are significantly more likely to report tinnitus (Fig. 1, high risk of tinnitus) than those with congenital hearing loss (Graham, 1987) (Fig. 1, low risk of tinnitus). However, limited data are available on this topic; and in existing studies, it is not always possible to determine when congenital hearing loss occurred. For example, a mid- to late-pregnancy infection, or a peripartum event, such as anoxia or the administration of aminoglycoside antibiotics, may cause early deafening after some weeks or months of intrauterine auditory experience. Two clinical studies, however, indicated that tinnitus may indeed be absent in the population that has had no auditory experience. In children with a Gap junction beta-2 protein (GJB2) mutation, for whom a complete lack of auditory experience can be surmised, there was a near absence of tinnitus (Tsukada et al., 2010). Moreover, a recent study found a relationship between deafness and the absence of tinnitus, even for congenital single-sided deafness (S. Y. Lee et al., 2017). In that study, strikingly, none of the 20 subjects with congenital deafness perceived tinnitus on the affected side (Fig. 1, congenital deafness), whereas 30 of 44 subjects with acquired singlesided deafness did experience tinnitus on the affected side (S. Y. Lee et al., 2017) (Fig. 1, acquired deafness). In contrast to congenitally deaf patients, patients with normal maturation who acquire sudden sensorineural hearing loss often experience tinnitus, with a prevalence of $60 \%-90 \%$, often on the deaf side (Fig. 1, high risk of tinnitus) (Van de Heyning et al., 2008; Chadha et al., 2009; Eggermont and Kral, 2016).

Based on the findings described above, it was concluded that the development of tinnitus needs to be preceded by auditory experience (Eggermont and Kral, 2016; S. Y. Lee et al., 2017). Specifically, it was suggested that the emergence of tinnitus requires the preexistence of a tonotopic map as a reference for the integration of sensory input to "somatic memory" (Eggermont and Kral, 2016). But the proper topographically ordered connections are established in the auditory pathway well before hearing actually functions (Friauf and Lohmann, 1999; Clause et al., 2014). Additionally, tonotopic maps in the brain persist in mice with profound deafness, independently of whether the hearing loss is acquired or congenital (Babola et al., 2018). Therefore, tonotopy, per se, is unlikely to cause tinnitus. Instead, a sensory experience-dependent maturation step must be required for the emergence of tinnitus.

\section{Maturation steps that require auditory experience}

Because hearing appears to be essential for the development of tinnitus, properties that arise after the onset of hearing are more likely to contribute to tinnitus than properties that emerge before hearing onset. One property that develops after hearing onset is the brain's SFR. The developing brain is hyperexcitable because neurons that release $\gamma$-aminobutyric acid (GABAergic neurons) are excitatory at this time. The effects of GABA depend on the chloride gradient across the plasma membrane, which in developing neurons favors chloride efflux and depolarization. A maturational shift in chloride transporters is required to reverse the chloride gradient so that GABA becomes inhibitory (Marin and Rubenstein, 2001; Ben-Ari, 2002) (Fig. 2A,B, green plus signs). This process is predicted to be dependent on BDNF, which has been shown to facilitate the expression of potassium chloride cotransporter 2 (KCC2) (Wardle and Poo, 2003), which contributes to this switch (De Koninck, 2007). This excitatoryto-inhibitory switch in GABAergic signaling occurs after tangentially migrating inhibitory neurons have successfully reached their destinations in higher brain regions, a process accomplished in rodents around birth (Marin and Rubenstein, 2001). In the auditory system, the switch occurs in a region-specific pattern after hearing onset (Kandler and Friauf, 1995; Friauf et al., 2011), possibly driven by sensory experience (Shibata et al., 2004) (Fig. 2A,C, orange minus signs).

We hypothesize that not hearing experience, per se, but fast auditory processing resulting from maturation of a distinct auditory fiber type after hearing onset is critical for the BDNFand sensory experience-dependent maturation of inhibitory GABAergic circuits in the auditory system. Whereas at the beginning of hearing onset, auditory fibers with low SFRs (Fig. 2B, low-SR, green fiber) and high activation thresholds (Yates, 1991; Merchan-Perez and Liberman, 1996) dominate, after hearing onset, $\sim 60 \%$ of auditory fibers develop high SFRs (Fig. $2 C$, high$\mathrm{SR}$, orange fiber) and low activation thresholds (Merchan-Perez and Liberman, 1996; Glowatzki and Fuchs, 2002; Grant et al., 2010). These high-SR fibers determine the threshold of the summed auditory-nerve response, measured by the compound action potential (Bourien et al., 2014), and are responsible for the shortest-latency auditory responses at any given characteristic frequency. Therefore, fast (high-SR) auditory fibers are suggested to determine perceptual thresholds (Meddis, 2006; Heil et al., 2008). Hence, high-SR auditory fibers likely contribute to lowered thresholds and shortened latency of cortical auditory responses, which can be measured after the sharpening of cortical receptive fields (Fig. 2C, cortical resolution $\Uparrow$ ) (de VillersSidani et al., 2007) at the end of the critical period after hearing onset: between P10 and P14 in rodents (de Villers-Sidani et al., 2007) and between the 27th embryonic week and sixth to 12th months after birth in humans (Neville and Bavelier, 2002). The sharpening of receptive fields, moreover, leads to narrower bandwidth responses, likely as a result of stimulus-evoked release of BDNF from cortical pyramidal neurons, which is suggested to trigger synaptogenesis in a complex network of fast-spiking PVexpressing GABAergic interneurons $\left(\mathrm{PV}^{+}\right.$interneurons) that provide perisomatic and dendritic inhibition to cortical pyramidal neurons (Fig. $2 C$, cortical resolution $\uparrow, \mathrm{BDNF} \uparrow, \mathrm{PV} \Uparrow$ ) (Hong et al., 2008; Xu et al., 2010; Lehmann et al., 2012; Griffen and Maffei, 2014). Fast-spiking, $\mathrm{PV}^{+}$interneurons play a key role in several higher microcircuit functions, such as feedforward and feedback inhibition, high-frequency network oscillations, and pattern separation. For all of these functions, the fast signaling properties of these neurons play a critical role (Hu et al., 2014, 2018). Notably, fast-spiking $\mathrm{PV}^{+}$interneuron networks develop in auditory subcortical and cortical projections with sensory experience (Lohmann and Friauf, 1996; Chumak et al., 2016), as also described for other sensory systems (Itami et al., 2007; Xu et al., 2010; Lehmann et al., 2012; Kimura and Itami, 2019).

In further support of our hypothesis, fast (high-SR) auditory fiber activity was related to the development of perisomatic $\mathrm{PV}^{+}$ interneuron inhibition and the enlargement of dynamic range of auditory responses after hearing onset (Chumak et al., 2016). Perisomatic $\mathrm{PV}^{+}$interneuron activity contributes to feedforward inhibition that narrows the window for temporal summation of EPSPs and action potential initiation in principle neurons (Pouille and Scanziani, 2001) and thereby promotes both sharpening of receptive fields and pattern separation (Leutgeb et al., 2007). Because maturation of fast (high-SR) auditory fiber activity was also linked to enhanced auditory fidelity, including increased inhibitory strength and shortened latencies (Xu et al., 2010; Chumak et al., 2016), we may predict that fast (high-SR) auditory fiber activity also contributes to $\mathrm{PV}^{+}$interneuronmediated feedback inhibition at principal-cell dendrites (Couey 


\section{A Low Risk of Tinnitus Hearing onset High Risk of Tinnitus}

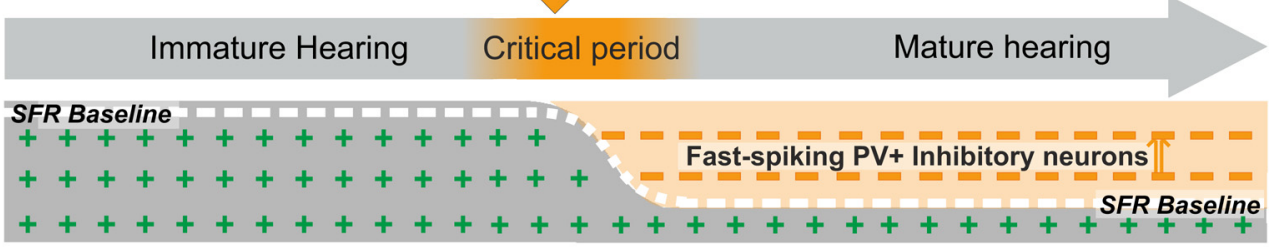

B

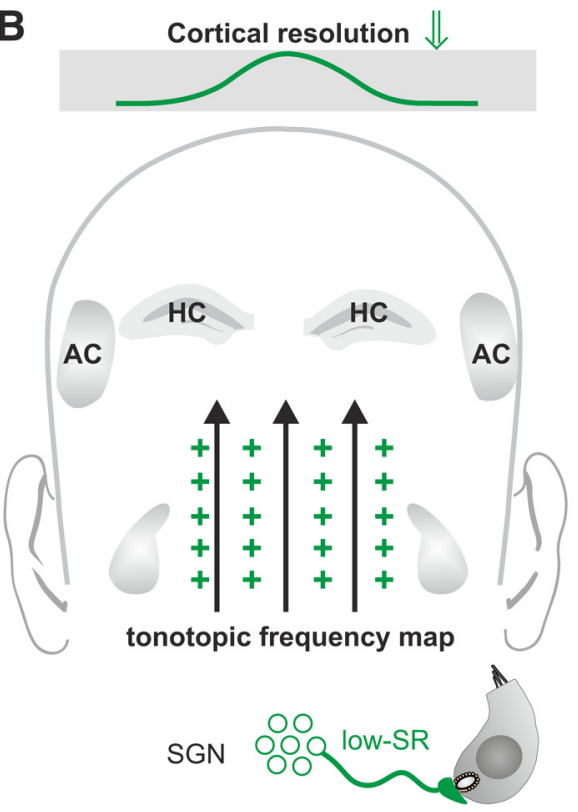

C
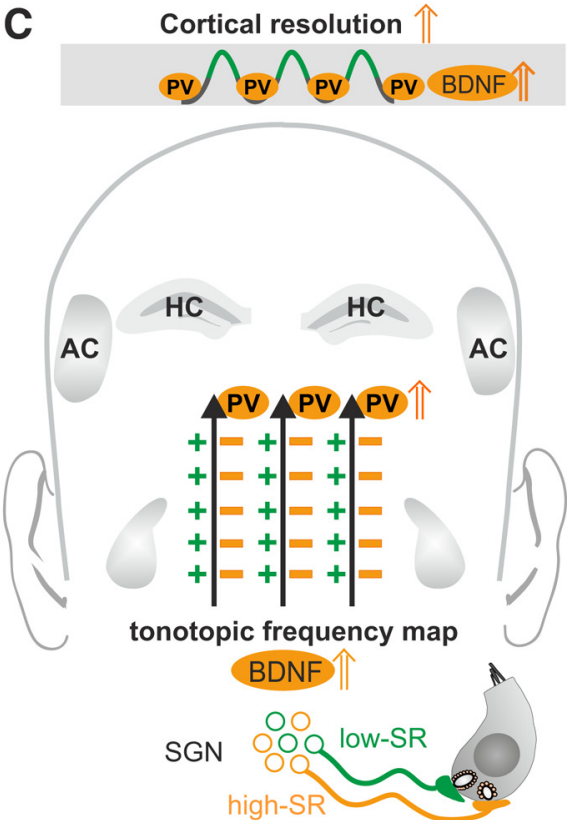

Figure 2. Diagram of auditory excitatory and inhibitory states before $(\boldsymbol{A}$, left, $\boldsymbol{B})$ and after $(\boldsymbol{A}$, right, $\boldsymbol{C})$ the critical period. $\boldsymbol{A}$, Immature hearing and congenital deafness go along with a low risk of tinnitus. In this state, GABAergic neurons still act in an excitatory manner (green + ) on the SFR in the brain (white dashed line). When GABA becomes inhibitory after the critical period (orange minus), the lower SFR baseline may initiate a high risk of tinnitus. $\boldsymbol{B}$, At hearing onset, auditory fibers with low SFRs (low-SR, green) can already be recorded along the tonotopic frequency map (black arrows) when GABAergic neurons in the ascending path are likely still excitatory. At that time, excitation dominates over inhibition (green + ) and auditory discrimination capacity is not yet specific for distinct sensory modalities (low cortical resolution, green downward arrow). C, With sensory experience, fast and specific auditory processing evolves with the development of fibers with high-spontaneous rate characteristics (high-SR, orange) and the maturation of inhibitory circuits (fast spiking PV ${ }^{+}$interneuron network, orange minus). The high-SR fibers may drive BDNF secretion from ascending auditory projection neurons up to the AC in a stimulus-dependent way. BDNF regulates perisomatic synaptic contacts between PV-positive interneurons and cortical pyramidal neurons, and sharpens auditory cortical resolution (orange upward arrow), enabling improved task performance. HC, Hippocampus; SGN, spiral ganglion neurons; $\uparrow$, increase; $\downarrow$, decrease.

et al., 2013), which has been shown to improve stimulus resolution and discrimination above noise in sensory systems (Caraiscos et al., 2004; Hu et al., 2014).

Given that fast inhibitory $\mathrm{PV}^{+}$interneurons are critical in generating both $\gamma$-(feedforward inhibition) and $\beta$-frequency oscillations (feedback inhibition) measured with EEG (Cardin et al., 2009; Sohal et al., 2009; Chen et al., 2017), experiments that used optogenetic disruption of inhibitory networks may help to explain changes in oscillations in tinnitus: Through optogenetic suppression of $\mathrm{PV}^{+}$interneuron activity, likely including tonic and phasic activity, increased synchronization of spontaneous activity across a broad frequency range was observed, leading to increased baseline spontaneous $\gamma$ power and occlusion of changes in evoked $\gamma$ power (Chen et al., 2017). Interestingly, increased baseline spontaneous $\gamma$ power linked with reduced evoked $\gamma$ power was observed in children with deficits in fast auditory processing (Mamashli et al., 2017), strengthening the hypothesis that diminished fast (high-SR) auditory fiber processing might also be able to cause enhanced baseline spontaneous $\gamma$ power and reduced evoked $\gamma$ power, a predicted correlate of tinnitus (see Proposed neural correlates of tinnitus reflected in the context of fast auditory processing). Elevated activity in fast- spiking $\mathrm{PV}^{+}$interneurons is predicted to play a role in improved task performance and attention-driven contrast amplification (Cardin et al., 2009; Kim et al., 2016; Chen et al., 2017). We therefore suggest that diminished fast (high-SR) auditory fiber activity reduces the ability of listeners to properly attend to relevant stimuli while ignoring irrelevant stimuli (Delano et al., 2007; Nunez and Malmierca, 2007; Wittekindt et al., 2014; Dragicevic et al., 2019), which is another neural correlate of tinnitus (see Proposed neural correlates of tinnitus reflected in the context of fast auditory processing).

It remains to be clarified in future studies whether fast (highSR) auditory fibers stimulate the maturation of this complex $\mathrm{PV}^{+}$interneuron network by activating BDNF promoters and synaptogenesis of fast-spiking $\mathrm{PV}^{+}$interneuron with projecting neurons, as has been suggested to occur in auditory and other sensory cortices (Itami et al., 2007; Xu et al., 2010; Lehmann et al., 2012; Kimura and Itami, 2019) or if BDNF acts via the facilitation of inhibitory actions by GABA (De Koninck, 2007). Regardless, both the maturation of fast auditory fibers that drive BDNF promoters and BDNF-driven faciliation of GABA-mediated inhibition would lower the baseline SFR in pyramidal neurons in cortical and functionally connected networks with 
auditory experience (Fig. $2 A$, SFR baseline, white dashed line $\Downarrow$ ). The initial hyperexcitability in these circuits resulting from GABAergic neurons being excitatory would thereby be reduced and the fidelity and specificity of responses to auditory input would become enhanced, as hypothesized for the auditory system (Chumak et al., 2016; Matt et al., 2018) and cerebellum (Duguid et al., 2012).

Regarding the lower risk of tinnitus in congenital deafness and the prediction that tinnitus requires auditory experience in children (see above), it is interesting to consider when fast (high$\mathrm{SR})$ auditory fibers and $\mathrm{PV}^{+}$interneurons, whose activity is reflected in $\gamma$ - and $\beta$-frequency oscillations (Cardin et al., 2009; Sohal et al., 2009; Gill and Grace, 2014; Chen et al., 2017), might mature in children. $\gamma$ oscillations develop in humans between the onset of hearing function before birth, approximately between the 27th embryonic week and sixth to 12th months after birth (Neville and Bavelier, 2002), with predictions that increased $\gamma$ oscillations, associated with feedforward inhibition, precede the development of increased $\beta$ oscillations (reflecting feedback inhibition) before 6 months after birth (Sowell et al., 2001; OrtizMantilla et al., 2016). From sixth months onwards, the development of functional connectivity in children's brains proceeds, becoming more clustered and specific for sensory modalities (Sowell et al., 2001; Neville and Bavelier, 2002; Ortiz-Mantilla et al., 2016), a process that is paralleled by enhanced speech comprehension in noise (Obleser et al., 2007; Youssofzadeh et al., 2018) and improvement of attention-driven contrast amplification for auditory stimuli, improved auditory discrimination capacity, and improved temporal discrimination (Sowell et al., 2001; Miller and Buschman, 2013) (Fig. 2C, cortical resolution). We thus can conclude that maturation of fast (high-SR) auditory fiber processing and inhibitory $\mathrm{PV}^{+}$interneuron microcircuits mature in the first months after birth, providing a good rationale for tinnitus occurring with low prevalence in congenital deafness but with high prevalence in acquired deafness (see above).

We conclude that the onset of fast (high-SR) auditory nerve fiber activity with the onset of auditory experience stimulates the development of a feedforward $\mathrm{PV}^{+}$interneuron network that is a prerequisite for the development and maintenance of feedback inhibitory $\mathrm{PV}^{+}$interneuron networks in auditory-specific circuits. The lack of fast auditory processing distinguishes congenital deafness, with a low risk of tinnitus (Fig. $2 B$ ), from mature acquired hearing loss, with a high risk of tinnitus (Fig. 2C).

\section{Proposed neural correlates of tinnitus reflected in the context of fast auditory processing}

We next reflect on the various predicted neural correlates of tinnitus in the context of fast (high-SR) auditory nerve activity and its predicted functions for central auditory processing described above.

\section{Neural gain}

Most previous tinnitus literature suggested that tinnitus is the result of homeostatic increases in central neural gain (see Introduction). We argue against the hypothesis that tinnitus results from neural gain-related hyperexcitability, instead suggesting that central neural gain describes a compensating central response to hearing loss that is not related to tinnitus, as explicated in the following. Central neural gain mechanisms typically include memory-dependent homeostatic modifications to restore the overall firing rate to its baseline or "setpoint" (Barnes et al., 2015; Gainey and Feldman, 2017). Considering that tonic $\mathrm{PV}^{+}$ interneuron activity may set baseline levels for homeostatic modifications, as discussed above, central neural gain would keep tonic $\mathrm{PV}^{+}$interneuron network activity, first established with auditory experience, intact. This may be different in the case of tinnitus, as will be discussed later in this review.

Central neural gain, which aims to restore an overall stable firing rate in neural networks after auditory deprivation (Fig. $3 \mathrm{~A}$, Neural gain $\Uparrow$ ), is predicted to require the strengthening of synapses via a learning-dependent, positive feedback cycle (for review, see Davis and Bezprozvanny, 2001; Rich and Wenner, 2007; Turrigiano, 2012). The occurrence of this in the auditory system can be concluded from the observation of compensating auditory output activity following reduced auditory input after mildly traumatic (100 dB SPL) sound exposure in mice. This neural gain is linked with elevated hippocampal long-term plasticity and with altered $\mathrm{PV}^{+}$interneuron labeling and enhanced BDNF promoter activity in auditory and hippocampal pathways (Matt et al., 2018). Such a complex brain response after auditory trauma is indicative of a positive feedback cycle that includes coactivation of auditory and frontostriatal circuits (for review, see Irvine, 2018b). Compensating central neural gain has moreover been observed after traumatic sound exposure in animals that did not exhibit tinnitus (Möhrle et al., 2019). Here, the restored late auditory brainstem response (ABR) ABR wave IV was linked with shortened response latencies (Möhrle et al., 2019), revealing that central neural gain may include shorter response latency and increased population-discharge synchrony, which are characteristics of attention-driven contrast amplification processes (Siegle et al., 2014; Kim et al., 2016; Chen et al., 2017; Galuske et al., 2019). We therefore propose that central neuron gain, and likewise, attention-driven contrast amplification of auditory responses, involves coactivation of auditory and frontostriatal regions, such as the following: (1) basal forebrain, to accentuate particular auditory stimuli (Fig. 3A) (Kilgard et al., 2002; Kraus and White-Schwoch, 2015; Irvine, 2018a); (2) inferior frontal gyrus activity (Fig. $3 A$ ), to distinguish new or deviant signals from previous ones (Schonwiesner et al., 2007; Malmierca et al., 2014); (3) hippocampus, to extract and memorize the behaviorally relevant signal (Kraus and White-Schwoch, 2015; Weinberger, 2015; Irvine, 2018a) and synaptic-adjusted strength (Fig. $3 A$, hippocampus); and (4) dlPFC and mPFC (Fig. 3A), to balance attention-driven plasticity responses (de Kloet, 2014; Irvine, 2018a; Viho et al., 2019) by inhibiting or enhancing stress responses (Sullivan and Gratton, 2002). We moreover suggest that only after auditory experience has enabled fast (high-SR) auditory fibers to stimulate the development of $\mathrm{PV}^{+}$inhibitory microcircuits, can BDNF promoters that are specifically activated by fast (high-SR) auditory fiber activity (Fig. 3A, BDNF介) drive the required compensating $\mathrm{PV}^{+}$microcircuit changes in the frontostriatal path, leading to restored ABR wave IV responses (neural gain) (Matt et al., 2018). This positive feedback cycle is not sufficient for initiating tinnitus, however, as suggested in previous studies (Knipper et al., 2013; Zeng, 2013; Sedley, 2019). Previous findings that link neural gain to tinnitus (Roberts et al., 2010; Norena, 2011; Schaette and Kempter, 2012; Shore et al., 2016) may be explained by unmatched hearing impairment between participants with and without tinnitus (Adjamian et al., 2009), or by the co-occurrence of tinnitus with decreased sound tolerance (hyperacusis) (Melcher et al., 2009; Hickox and Liberman, 2014; Auerbach et al., 2019; Möhrle et al., 2019).

In conclusion, we suggest that active feedforward and feedback $\mathrm{PV}^{+}$interneuron microcircuits, first established with the emergence of fast (high-SR) auditory fiber activity during auditory experience, form the base substrate on which overall firing 
A

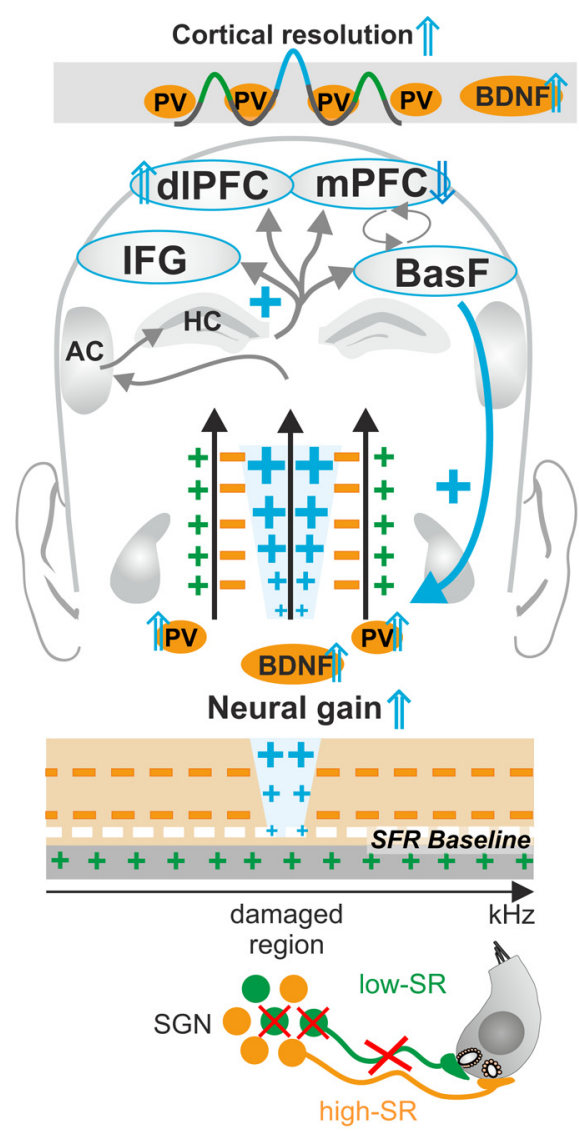

B Tinnitus

Cortical resolution $\Downarrow$ PV $\bigcirc P V$ BDNF $\downarrow$
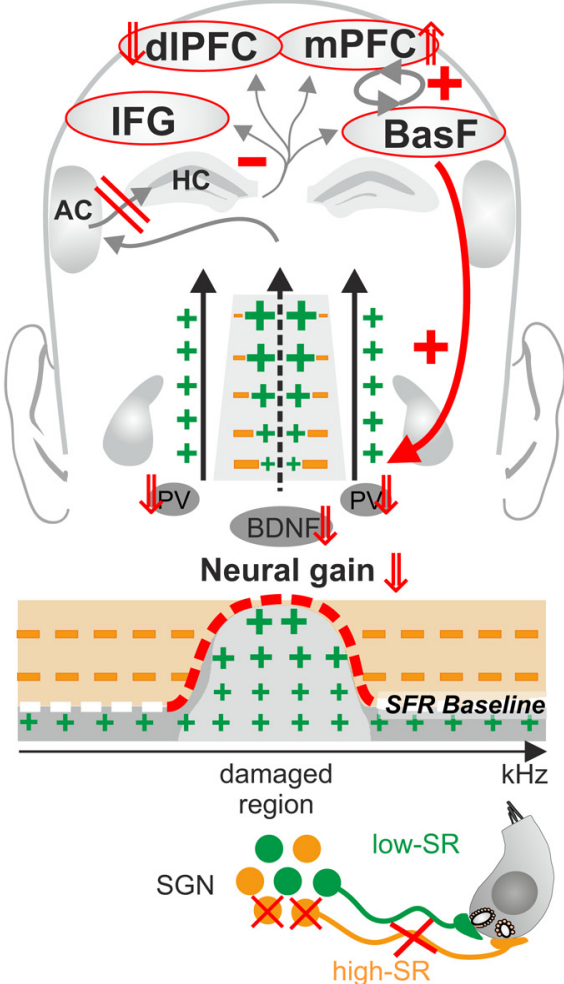

Figure 3. Predicted auditory gating in the absence $(\boldsymbol{A})$ and presence $(\boldsymbol{B})$ of tinnitus. $\boldsymbol{A}$, Auditory gating may lead to central neural gain, preventing tinnitus after mild acoustic trauma (damaged region). High-SR fiber-driven auditory processing may cause activity-dependent BDNF secretion from auditory-specific synapses. This context-specific signaling can be strengthened (blue + ) in a memory-dependent positive feedback cycle requiring activity in the basal forebrain (BasF, blue curved arrow), inferior frontal gyrus (IFG), and dIPFC and mPFC. This may lead to enhanced output activity relative to reduced input (Neural gain). $\boldsymbol{B}$, Failing central neural gain is predicted to result in tinnitus after severe or stressful acoustic trauma. The lack of high-SR fiber-driven auditory input in the damaged region critically reduces context-specific recruitment of activity-dependent BDNF, possibly essential to maintaining inhibitory, tonic PV-positive interneuron network activity. The baseline levels of spontaneous firing in affected frequency regions is enhanced by hyperexcitability (green + below red dashed line). The prefrontal stress control becomes unbalanced (mPFC up), which leads to uncoupling of auditory-specific and frontostriatal brain regions, resulting in the accentuation of irrelevant hyperexcitability-derived neuronal activity that would otherwise be ignored (tinnitus).

rates can be enhanced after hearing onset in response to hearing loss. However, this memory-dependent positive feedback cycle that leads to enhanced output activity after reduced auditory input (neural gain) is unlikely to be sufficient for tinnitus.

\section{Loss of GABAergic inhibition in tinnitus}

Numerous studies have suggested that the hyperexcitability linked to tinnitus is associated with acute GABAergic disinhibition in the ascending auditory pathway (Norena, 2011; Schaette and McAlpine, 2011; Schaette and Kempter, 2012; Norena and Farley, 2013; Auerbach et al., 2014; Kalappa et al., 2014; Eggermont and Tass, 2015; Gao et al., 2016; Sedley et al., 2016; Shore et al., 2016; Roberts, 2018; Roberts and Salvi, 2019). From a traditional position, this hyperexcitability has most often been interpreted as resulting from a central neural gain response (see Introduction). We go further in suggesting that the hyperexcitability rather results from critical loss of fast (high-SR) auditory drive that triggers reemergence of GABAergic excitation, instead of GABAergic inhibition (Ben-Ari, 2002).

A notable facet of tinnitus is its rapid onset after acquired deafness. For example, an immediate onset of tinnitus occurred in $60 \%-90 \%$ of cases in children with CIs when the implants were not in use (Van de Heyning et al., 2008; Chadha et al.,
2009). Likewise, acquired monaural or binaural sudden sensory hearing loss in rodents has been linked to disinhibition in nearly all ascending auditory nuclei (Abbott et al., 1999; Milbrandt et al., 2000; Mossop et al., 2000). In some cases in rodents, the generation of hyperexcitability was observed in auditory nuclei within a few minutes of deafening or nerve transection (McAlpine et al., 1997; Mossop et al., 2000). Thus, the time frame of hyperexcitability associated with acquired deafness in rodents is congruent with the fast onset of acute tinnitus after CIs are turned off in humans.

Given the rapid time scale (minutes to hours) of activity-dependent functional downregulation or upregulation of KCC2 (Khirug et al., 2010; H. H. Lee et al., 2011; Nardou et al., 2011), a reemergence of GABAergic excitation can occur within the time frame of acute tinnitus. Furthermore, auditory nerve transection has been shown to lead to a decline of KCC2 and a reemergence of depolarizing GABAergic signaling (Tighilet et al., 2016). To date, however, this has only been analyzed 3-30 d after auditorynerve transection (Tighilet et al., 2016). Considering that, in the auditory system, the GABAergic switch from depolarization to inhibition occurs in a region-specific pattern after hearing onset (Kandler and Friauf, 1995; Friauf et al., 2011) and BDNF-driven facilitation of inhibitory signaling by GABA (De Koninck, 2007) may be maintained through critical fast auditory fiber drive (see 
above), future studies are urgently needed to determine whether loss of fast (high-SR) fiber processing causes hyperexcitability in affected frequency regions by inducing reemergence of depolarizing GABAergic signaling, thus leading to tinnitus.

\section{Excessive cortical synchrony and enhanced $\gamma$ oscillations in tinnitus}

Hyperexcitability and a rapidly enhanced SFR during chronic tinnitus have both been linked to neuronal bursting and excessive neuronal synchrony in the AC (Norena and Farley, 2013; Eggermont and Tass, 2015). This abnormal neural synchrony has been suggested to be confined to specific oscillation frequency bands (Eggermont and Tass, 2015), particularly to enhanced spontaneous $\gamma$ oscillations $(30-80 \mathrm{~Hz})$, which were observed in tinnitus patients (Weisz et al., 2007; Ortmann et al., 2011; Vanneste et al., 2019) and in animal models of tinnitus (Tziridis et al., 2015). Currently, the tinnitus theory of thalamocortical dysrhythmia describes enhanced $\gamma$ oscillations in tinnitus patients as an overactive feedback loop (De Ridder et al., 2015; Sedley, 2019; Vanneste et al., 2019). But we suggest that increased cortical synchrony in tinnitus might result from underactive, rather than overactive feedback inhibition, specifically from underactive tonic $\mathrm{PV}^{+}$interneuron activity in auditory microcircuits. We reason that, during tinnitus, a pathologic reduction of tonic (perisomatic) inhibition of cortical pyramidal neurons by monosynaptically coupled $\mathrm{PV}^{+}$interneurons in auditory circuits (Fig. 3B, PV $\Downarrow$ ) might diminish feedback inhibition. Under these conditions, pyramidal neurons would fire synchronously and independently of input. Such a reduction of tonic inhibition mediated by $\mathrm{PV}^{+}$interneurons leads to a rapid increase in bursting and a reduced signal-to-noise ratio in neurons in the cerebellum (Duguid et al., 2012) and has been discussed in the context of excessive cortical synchrony shown for epilepsy (Rossignol et al., 2013; Hsieh et al., 2017). Moreover, diminished activity in tonic fast-spiking $\mathrm{PV}^{+}$interneuron networks was shown in rodent models (Lodge et al., 2009; Gill and Grace, 2014) and in children with fast auditory processing deficits (Mamashli et al., 2017) linked with enhanced baseline spontaneous $\gamma$ power and reduced evoked $\gamma$ power. The same neurobiological deficits that lead to enhanced baseline spontaneous $\gamma$ power in children with fast auditory processing deficits (Mamashli et al., 2017), as is autism spectrum disorder, is also associated with elevated gap-discrimination thresholds and a diminished ability to detect short gaps (Foss-Feig et al., 2017), an often mentioned phenotypical characteristic of tinnitus (Fournier and Hebert, 2013; Lobarinas et al., 2013; Galazyuk and Hebert, 2015).

We therefore suggest that the excessive cortical synchrony and enhanced spontaneous $\gamma$ oscillations observed in tinnitus patients and tinnitus animal models (Weisz et al., 2007; Ortmann et al., 2011; Tziridis et al., 2015; Vanneste et al., 2019) may be related to reduced tonic activity in $\mathrm{PV}^{+}$interneuron microcircuits resulting from critical diminution of fast (high-SR) auditory fiber drive.

\section{Stochastic resonance as a putative cause of tinnitus}

A predicted noise source located within the somatosensory system has been suggested to drive a stochastic resonance mechanism at the level of the dorsal cochlear nucleus during tinnitus (Krauss et al., 2016, 2017). Stochastic resonance is a phenomenon that may occur whenever noise helps to lift a subthreshold input signal above a threshold. This noise source was hypothesized to be upregulated, for example, following reduced cochlear input, and to contribute to central hyperexcitability that on short time scales of milliseconds to seconds could be amplified through neural gain and thereby contribute to a tinnitus percept (Krauss et al., 2016, 2017). Within our proposed framework, we suggest that the noise source that lifts SFR above threshold results from elevated SFRs in dispersed auditory-specific regions as a consequence of critically reduced fast auditory processing and loss of tonic $\mathrm{PV}^{+}$interneuron activity in auditory microcircuits. In such cases, the stimulus resolution and specificity for the particular sensory modality would be reduced and stochastic resonance may manipulate the excitability at the level of the dorsal cochlear nucleus.

\section{Disrupted auditory/frontostriatal connectivity and impaired noise cancellation as correlates of tinnitus}

Numerous studies have suggested that dysregulation in frontostriatal brain regions and the limbic system is a neural correlate of tinnitus (Muhlau et al., 2006; Vanneste and De Ridder, 2012; Schmidt et al., 2017). More specifically, disruption of a frontostriatal network has been suggested to contribute to tinnitus by impairing "noise cancellation" (Rauschecker et al., 2015).

We here suggest that a dysregulation of frontostriatal microcircuits in tinnitus can be well explained through reduced tonic activity in $\mathrm{PV}^{+}$interneuron microcircuits that are diminished after critical loss of fast (high-SR) fibers. A critical reduction of fast (high-SR) auditory processing was suggested to be a correlate of tinnitus (Knipper et al., 2013; Hofmeier et al., 2018; Möhrle et al., 2019), as it is expected to impair fast communication between auditory-specific and frontostriatal regions and would therefore diminish memory-dependent adjustment of stimulus-evoked responses following, for example, acoustic trauma. This was verified in tinnitus patients through a reduced and delayed late ABR wave $\mathrm{V}$ linked to reduced sound-evoked blood oxygenation level dependent (BOLD) functional magnetic resonance imaging (fMRI) activity in the AC (Hofmeier et al., 2018; Koops et al., 2020), reduced functional connectivity observed during soundevoked activity (Boyen et al., 2014; Lanting et al., 2014), and reduced resting-state functional connectivity ( $\mathrm{r}-\mathrm{fc}$ )MRI connectivity between auditory-specific brain regions and frontostriatal regions (Leaver et al., 2016; Hofmeier et al., 2018).

Disrupted functional connectivity between auditory-specific and frontostriatal regions (Fig. $3 B$ ) is expected to result in a breakdown of contrast amplification, which accentuates relevant over irrelevant stimuli (Delano et al., 2007; Dragicevic et al., 2019). Importantly, contrast amplification relies on an intact temporal, top-down feedback circuit and on intact fast $\mathrm{PV}^{+}$ interneuron activity (Cardin et al., 2009; Kim et al., 2016; Chen et al., 2017). As a result of critically impaired fast (high-SR) auditory fiber processing and the resulting diminished drive to tonic inhibitory $\mathrm{PV}^{+}$interneuron microcircuits (see above), central hyperexcitability in deprived frequency regions may occur. Because this hyperactivity cannot be suppressed through contrast amplification processes, it results in the perception of phantom sounds (tinnitus).

In summary, critical reduction in fast (high-SR) auditory fiber processing after auditory trauma can reduce functional connectivity between auditory-specific regions and frontostriatal microcircuits and thereby impair neural processing that allows one to ignore spurious activity in the deprived auditory regions.

\section{Impaired attention/stress control as a correlate of tinnitus}

In tinnitus patients, a tinnitus precursor has been suggested to exist, but it is normally ignored as imprecise evidence against the prevailing percept of "silence" (Sedley et al., 2016). This 

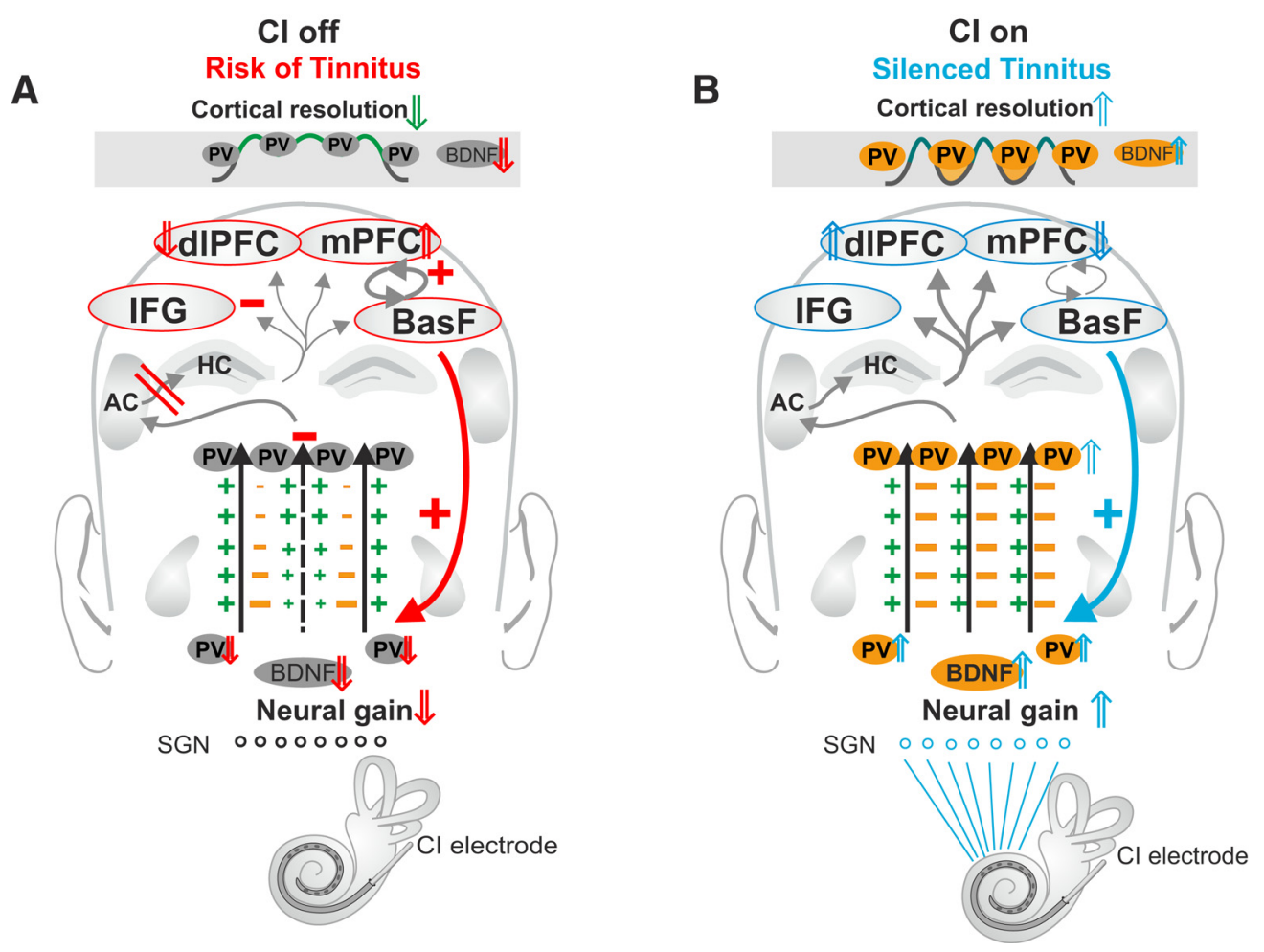

Figure 4. Predicted auditory processing states after cochlear implantation. $\boldsymbol{A}, \mathrm{Cl}$ off. $\boldsymbol{B}, \mathrm{Cl}$ on. $\boldsymbol{A}$, Tinnitus occurs with high prevalence when congenital deafness is treated with a $\mathrm{Cl}$ and the implant is not in use. Under these conditions, the activity fails to serve as the driving force for context-specific secretion of BDNF. When switching off the implant, initial hyperexcitability would reemerge and on loss of auditory-specific control of frontostriatal coupling would lead to accentuation of irrelevant neural activity in deprived regions basal forebrain (BasF, red curved arrow) leading to Risk of Tinnitus. $\boldsymbol{B}$, With electrical stimulation, the driving force for context-specific secretion of BDNF may be partially reinstalled. The initial hyperexcitability would be suppressed in deprived regions as irrelevant neuronal information (Silenced Tinnitus).

precursor is amplified (1) through focused attention (Sedley et al., 2016); (2) through fear, anxiety, or stress (Jastreboff et al., 1996); or (3) through a combination of these facilitators that influence individual tinnitus severity, depending on the context of each individual's culture and experience (Searchfield, 2014).

The conscious perception of a tinnitus precursor through focused attention has been discussed in the context of a prediction error in auditory sensation (Sedley et al., 2016; Hullfish et al., 2019). Auditory predictions can only be made, however, after learning about predictable, relevant, auditory signals as distinct from those that are irrelevant. The remembrance of predictable stimuli requires fast (high-SR) auditory fiber activity and maturation of $\mathrm{PV}^{+}$interneuron networks that develop only with sensory experience. We hypothesize that a prediction error might be caused by hyperexcitability resulting from impaired tonic $\mathrm{PV}^{+}$ interneuron activity. This hyperexcitability produces activity that cannot be suppressed by contrast amplification processes, as discussed in the previous section (Fig. 3B, impaired SSR baseline, red dashed line).

In the Jastreboff Neurophysiological Model of tinnitus, fear, anxiety, or stress is predicted to be involved in the emergence of "pre-tinnitus activity" that, in subjects without symptoms, is typically ignored (Jastreboff et al., 1996). We suggest that elevated hyperexcitability following the loss of fast (high-SR) auditory fiber processing can lead to imbalanced stress control by disturbing functional connections between auditory-specific regions and the medial prefrontal cortex (mPFC) and dorsolateral prefrontal cortex (dlPFC). While mPFC is assumed to play a role in the activation of stress responses, dlPFC has been found to be linked to inhibition of stress responses (McKlveen et al., 2016). Correspondingly, it was observed that, during tinnitus, resting- state connectivity involving $\mathrm{MPFC}$ and dlPFC was disturbed (Schecklmann et al., 2012; Leaver et al., 2016; Hofmeier et al., 2018) (Fig. 3B, mPFC介, dlPFC $\Downarrow$ ).

Conscious percepts of sound may be encoded not only in the AC but also in PFC regions (de Lafuente and Romo, 2005). Unbalanced PFC activity might impact the tinnitus percept itself. According to this view, the observed reduction in selective attention for stimuli outside the tinnitus frequency, but increased vigilance for sounds approximating the tinnitus frequency seen in tinnitus patients (Mazurek et al., 2017; Brozoski et al., 2019) can be considered to be a response to a critically diminished auditory-specific drive after reductions in fast (high-SR) fiber activity and subsequent reduction of PFC-dependent contrast amplification of auditory information (Fig. 3B, red curved arrow).

Finally, the individual variability of stress sensitivity might contribute to the observed individually high variability of and susceptibility to tinnitus (Searchfield, 2014; Durai et al., 2017) through, for example, a predicted stress vulnerability for auditory fibers (Singer et al., 2018) or an individual variability in the apparent high metabolic vulnerability of particular $\mathrm{PV}^{+}$interneuron synapses (Kann, 2016).

In summary. in tinnitus patients, impaired PFC-triggered attention/stress control following reduced fast (high-SR)-auditory fiber activity may be linked to a reduced ability to habituate to, or ignore, enhanced hyperexcitability in critically deprived frequency regions.

Tinnitus can be suppressed when CIs are turned on but induced when turned off

CIs are the most successful treatment of choice for auditory rehabilitation of patients with severe to profound sensory 
deafness (Kral and O’Donoghue, 2010; Wilson, 2017). Electrical stimulation of the auditory nerve via CIs probably reestablishes crucial central functions for fast auditory processing by initiating activity in high-SR fibers. This must be concluded from the success in achieving nearly normal speech and language development in congenitally deaf children (Rajan et al., 2018; Albalawi et al., 2019). This partial implementation of fast auditory processing through CIs may also be reflected in the observed shortened response-onset latencies observed after cochlear electrode implantation in cats (Tillein et al., 2016).

Strikingly, in children implanted between 3 and 15 years, tinnitus occurred most commonly on the implanted side when the implants were not in use (e.g., in bed at night) (Chadha et al., 2009). The incidence of tinnitus is $70 \%-90 \%$ of cases when a CI, implanted following severe bilateral hearing loss, is turned off (Baguley and Atlas, 2007; Ramakers et al., 2015) (Fig. 4A, CI Off: Risk of Tinnitus). In contrast, increasing evidence suggests that, on full-electrode stimulation through bilateral CI implants, tinnitus is suppressed (Fig. 4B, CI On: Silenced Tinnitus) (Baguley and Atlas, 2007; Tyler et al., 2008b; Punte et al., 2013; Knopke et al., 2017). Also, in patients with unilateral hearing loss, the implantation of a CI suppressed tinnitus (Punte et al., 2013). When tested in their capacity to suppress tinnitus, electric-acoustic stimulation (Mertens et al., 2018; Pillsbury et al., 2018; Li et al., 2019), as well as hearing aids (Searchfield et al., 2010; Shekhawat et al., 2013), have resulted in at least transient tinnitus relief.

We therefore predict that ongoing electrical stimulation of the auditory pathway may be a prerequisite for the suppression of tinnitus. In the future, either persistent stimulation near threshold or stimulation of frequency regions higher than $8 \mathrm{kHz}$ (Levy et al., 2015), which are often not reliably covered in hearing aids or CI, should be investigated as a driving force to maintain or reestablish tonic $\mathrm{PV}^{+}$interneuron activity in auditory-specific microcircuits. Thereby appropriate activities for auditory-specific contrast amplification may be reinstated.

In summary, auditory experience through initial CI stimulation is potentially sufficient to drive feedforward and feedback $\mathrm{PV}^{+}$interneuron microcircuits in auditory-specific circuits, and this may be a prerequisite for a tinnitus percept to occur in a deaf ear when the CI is turned off. Electrical stimulation of the active $\mathrm{CI}$ is however essential to suppress the tinnitus percept.

\section{Conclusion and future perspectives}

In conclusion, we consider that congenital deafness (with a low risk of tinnitus) differs from acquired deafness (with high risk of tinnitus). With acquired deafness, the maturation of fast (highSR) auditory fiber processing and emergence of specific inhibitory $\mathrm{PV}^{+}$interneuron microcircuits, essential for accentuation of relevant over irrelevant auditory stimuli, have already taken place. This maturation does not occur in congenital deafness because of the lack of auditory experience. In this view, fast (high-SR) auditory fiber characteristics developing after hearing onset provide the drive to establish feedforward and feedback $\mathrm{PV}^{+}$interneuron microcircuits and to maintain feedback $\mathrm{PV}^{+}$ interneuron microcircuits required for memory-linked reinforcement processes. Upon critical loss of fast (high-SR) auditory fiber processing, hyperexcitability reemerges through loss of tonic $\mathrm{PV}^{+}$interneuron activity and reversion to depolarizing GABAergic signaling. Tinnitus sufferers cannot ignore the auditory percepts resulting from this hyperexcitability, and this promotes further alertness to the phantom noise (Figs. 3B, 4A, red curved arrow, tinnitus).
Fast (high-SR) auditory fiber processing cannot be lost in either congenital bilateral or single-sided deafness because it was never established. Upon cochlear implantation, however, part of the fast auditory processing circuit may develop or be reestablished, albeit with lower resolution (Fig. 4A, Risk of Tinnitus). In CI-ON mode, electrical stimulation through CI may be able to install context-specific recruitment of contrast amplification mechanisms, enabling the suppression of tinnitus (Fig. $4 B$, Silenced Tinnitus).

The present article is premised on the hypothesis that various tinnitus subtypes and mechanisms have a final common pathway that acts between the onset of hearing loss and the appearance of the tinnitus percept. Future studies should investigate whether other tinnitus etiologies (Henry et al., 2014; Moller et al., 2015) may be related to the framework suggested here. In this context, (1) the extreme sensitivity and vulnerability of particular inhibitory $\mathrm{PV}^{+}$interneuron synapses to any metabolic fatigue or shortfall (Kann, 2016), or (2) the observation that on injury/ trauma or glial inflammation a pathologic GABA signaling, that is, excitatory instead of inhibitory (Shih et al., 2017), should be considered as triggers for tinnitus.

In a unified effort across the tinnitus community, tinnitus research (1) could focus on whether a selective loss of one population of auditory nerve fibers (low-SR or high-SR) can explain why some people acquire tinnitus and other do not; (2) may investigate the fragility of fast (high-SR) auditory fiber processing under stress, comorbidities, traumatic, or inflammatory events; (3) should search for pharmaceutical or neuromodulatory tools that enable noninvasive reinstatement of a driving force to maintain feedback fast-inhibitory $\mathrm{PV}^{+}$interneuron microcircuits and feedback control of frontostriatal, attentional and stress-controlling circuits; (4) might explicitly analyze the restorative capacity of the identified feedback mechanisms through noninvasive neurostimulation devices, customized sound therapies, CIs, or medications; and (5) explore the relationship between positive effects of CI and cognition (Ramakers et al., 2015; Bruggemann et al., 2017; Knopke et al., 2017) in the context of fast (high-SR) auditory fiber processing and suppression of tinnitus and other comorbidities.

\section{References}

Abbott SD, Hughes LF, Bauer CA, Salvi R, Caspary DM (1999) Detection of glutamate decarboxylase isoforms in rat inferior colliculus following acoustic exposure. Neuroscience 93:1375-1381.

Adjamian P, Sereda M, Hall DA (2009) The mechanisms of tinnitus: perspectives from human functional neuroimaging. Hear Res 253:15-31.

Albalawi Y, Nidami M, Almohawas F, Hagr A, Garadat SN (2019) Categories of auditory performance and speech intelligibility ratings in prelingually deaf children with bilateral implantation. Am J Audiol 28:62-68.

Auerbach BD, Rodrigues PV, Salvi RJ (2014) Central gain control in tinnitus and hyperacusis. Front Neurol 5:206.

Auerbach BD, Radziwon K, Salvi R (2019) Testing the central gain model: loudness growth correlates with central auditory gain enhancement in a rodent model of hyperacusis. Neuroscience 407:93-107.

Babola TA, Li S, Gribizis A, Lee BJ, Issa JB, Wang HC, Crair MC, Bergles DE (2018) Homeostatic control of spontaneous activity in the developing auditory system. Neuron 99:511-524.e515.

Baguley DM, Atlas MD (2007) Cochlear implants and tinnitus. Prog Brain Res 166:347-355.

Baguley DM, McFerran DJ (2002) Current perspectives on tinnitus. Arch Dis Child 86:141-143.

Barnes SJ, Sammons RP, Jacobsen RI, Mackie J, Keller GB, Keck T (2015) Subnetwork-specific homeostatic plasticity in mouse visual cortex in vivo. Neuron 86:1290-1303.

Bauer CA (2018) Tinnitus. N Engl J Med 378:1224-1231. 
Bauer CA, Brozoski TJ, Myers K (2007) Primary afferent dendrite degeneration as a cause of tinnitus. J Neurosci Res 85:1489-1498.

Bauer CA, Turner JG, Caspary DM, Myers KS, Brozoski TJ (2008) Tinnitus and inferior colliculus activity in chinchillas related to three distinct patterns of cochlear trauma. J Neurosci Res 86:2564-2578.

Ben-Ari Y (2002) Excitatory actions of gaba during development: the nature of the nurture. Nat Rev Neurosci 3:728-739.

Bourien J, Tang Y, Batrel C, Huet A, Lenoir M, Ladrech S, Desmadryl G, Nouvian R, Puel JL, Wang J (2014) Contribution of auditory nerve fibers to compound action potential of the auditory nerve. J Neurophysiol 112:1025-1039.

Boyen K, de Kleine E, van Dijk P, Langers DR (2014) Tinnitus-related dissociation between cortical and subcortical neural activity in humans with mild to moderate sensorineural hearing loss. Hear Res 312:48-59.

Brozoski T, Wisner K, Randall M, Caspary D (2019) Chronic sound-induced tinnitus and auditory attention in animals. Neuroscience 407:200-212.

Bruggemann P, Szczepek AJ, Klee K, Grabel S, Mazurek B, Olze H (2017) In patients undergoing cochlear implantation, psychological burden affects tinnitus and the overall outcome of auditory rehabilitation. Front Hum Neurosci 11:226.

Canlon B, Theorell T, Hasson D (2013) Associations between stress and hearing problems in humans. Hear Res 295:9-15.

Caraiscos VB, Elliott EM, You-Ten KE, Cheng VY, Belelli D, Newell JG, Jackson MF, Lambert JJ, Rosahl TW, Wafford KA, MacDonald JF, Orser BA (2004) Tonic inhibition in mouse hippocampal CA1 pyramidal neurons is mediated by $\alpha 5$ subunit-containing gamma-aminobutyric acid type A receptors. Proc Natl Acad Sci USA 101:3662-3667.

Cardin JA, Carlen M, Meletis K, Knoblich U, Zhang F, Deisseroth K, Tsai LH, Moore CI (2009) Driving fast-spiking cells induces gamma rhythm and controls sensory responses. Nature 459:663-667.

Chadha NK, Gordon KA, James AL, Papsin BC (2009) Tinnitus is prevalent in children with cochlear implants. Int J Pediatr Otorhinolaryngol 73:671-675.

Chen G, Zhang Y, Li X, Zhao X, Ye Q, Lin Y, Tao HW, Rasch MJ, Zhang X (2017) Distinct inhibitory circuits orchestrate cortical beta and gamma band oscillations. Neuron 96:1403-1418.e1406.

Chumak T, Rüttiger L, Lee SC, Campanelli D, Zuccotti A, Singer W, Popelárõ J, Gutsche K, Geisler HS, Schraven SP, Jaumann M, PanfordWalsh R, Hu J, Schimmang T, Zimmermann U, Syka J, Knipper M (2016) BDNF in lower brain parts modifies auditory fiber activity to gain fidelity but increases the risk for generation of central noise after injury. Mol Neurobiol 53:5607-5627.

Clause A, Kim G, Sonntag M, Weisz CJ, Vetter DE, Rübsamen R, Kandler K (2014) The precise temporal pattern of prehearing spontaneous activity is necessary for tonotopic map refinement. Neuron 82:822-835.

Couey JJ, Witoelar A, Zhang SJ, Zheng K, Ye J, Dunn B, Czajkowski R, Moser MB, Moser EI, Roudi Y, Witter MP (2013) Recurrent inhibitory circuitry as a mechanism for grid formation. Nat Neurosci 16:318-324.

Dallos P (2008) Cochlear amplification, outer hair cells and prestin. Curr Opin Neurobiol 18:370-376.

Davis GW, Bezprozvanny I (2001) Maintaining the stability of neural function: a homeostatic hypothesis. Annu Rev Physiol 63:847-869.

de Kloet ER (2014) From receptor balance to rational glucocorticoid therapy. Endocrinology 155:2754-2769.

De Koninck Y (2007) Altered chloride homeostasis in neurological disorders: a new target. Curr Opin Pharmacol 7:93-99.

de Lafuente V, Romo R (2005) Neuronal correlates of subjective sensory experience. Nat Neurosci 8:1698-1703.

De Ridder D, Vanneste S, Langguth B, Llinas R (2015) Thalamocortical dysrhythmia: a theoretical update in tinnitus. Front Neurol 6:124.

de Villers-Sidani E, Chang EF, Bao S, Merzenich MM (2007) Critical period window for spectral tuning defined in the primary auditory cortex (A1) in the rat. J Neurosci 27:180-189.

Delano PH, Elgueda D, Hamame CM, Robles L (2007) Selective attention to visual stimuli reduces cochlear sensitivity in chinchillas. J Neurosci 27:4146-4153.

Demeester K, van Wieringen A, Hendrickx JJ, Topsakal V, Fransen E, Van Laer L, De Ridder D, Van Camp G, Van de Heyning P (2007) Prevalence of tinnitus and audiometric shape. B-ENT 3:37-49.

Dragicevic CD, Marcenaro B, Navarrete M, Robles L, Delano PH (2019) Oscillatory infrasonic modulation of the cochlear amplifier by selective attention. PLoS One 14:e0208939.
Duguid I, Branco T, London M, Chadderton P, Hausser M (2012) Tonic inhibition enhances fidelity of sensory information transmission in the cerebellar cortex. J Neurosci 32:11132-11143.

Durai M, O'Keeffe MG, Searchfield GD (2017) Examining the short term effects of emotion under an Adaptation Level Theory model of tinnitus perception. Hear Res 345:23-29.

Durai M, Searchfield G (2016) Anxiety and depression, personality traits relevant to tinnitus: a scoping review. Int J Audiol 55:605-615.

Eggermont JJ, Kral A (2016) Somatic memory and gain increase as preconditions for tinnitus: insights from congenital deafness. Hear Res 333:37-48.

Eggermont JJ, Tass PA (2015) Maladaptive neural synchrony in tinnitus: origin and restoration. Front Neurol 6:29.

Foss-Feig JH, Schauder KB, Key AP, Wallace MT, Stone WL (2017) Audition-specific temporal processing deficits associated with language function in children with autism spectrum disorder. Autism Res 10:1845-1856.

Fournier P, Hebert S (2013) Gap detection deficits in humans with tinnitus as assessed with the acoustic startle paradigm: does tinnitus fill in the gap? Hear Res 295:16-23.

Friauf E, Lohmann C (1999) Development of auditory brainstem circuitry: activity-dependent and activity-independent processes. Cell Tissue Res 297:187-195.

Friauf E, Rust MB, Schulenborg T, Hirtz JJ (2011) Chloride cotransporters, chloride homeostasis, and synaptic inhibition in the developing auditory system. Hear Res 279:96-110.

Gainey MA, Feldman DE (2017) Multiple shared mechanisms for homeostatic plasticity in rodent somatosensory and visual cortex. Philos Trans R Soc Lond B Biol Sci 372:20160157.

Galazyuk A, Hebert S (2015) Gap-prepulse inhibition of the acoustic startle reflex (GPIAS) for tinnitus assessment: current status and future directions. Front Neurol 6:88.

Galuske RA, Munk MH, Singer W (2019) Relation between gamma oscillations and neuronal plasticity in the visual cortex. Proc Natl Acad Sci USA 116:23317-23325.

Gao Y, Manzoor N, Kaltenbach JA (2016) Evidence of activity-dependent plasticity in the dorsal cochlear nucleus, in vivo, induced by brief sound exposure. Hear Res 341:31-42.

Geven LI, de Kleine E, Free RH, van Dijk P (2011) Contralateral suppression of otoacoustic emissions in tinnitus patients. Otol Neurotol 32:315-321.

Gill KM, Grace AA (2014) The role of $\alpha 5 \mathrm{GABA}_{\mathrm{A}}$ receptor agonists in the treatment of cognitive deficits in schizophrenia. Curr Pharm Des 20:5069-5076.

Gilles A, Schlee W, Rabau S, Wouters K, Fransen E, Van de Heyning P (2016) Decreased speech-in-noise understanding in young adults with tinnitus. Front Neurosci 10:288

Glowatzki E, Fuchs PA (2002) Transmitter release at the hair cell ribbon synapse. Nat Neurosci 5:147-154.

Graham J (1987) Tinnitus in hearing-impaired children. In: Tinnitus (Hazell JWPH ed), pp 131-143. London: Churchill Livingstone.

Grant L, Yi E, Glowatzki E (2010) Two modes of release shape the postsynaptic response at the inner hair cell ribbon synapse. J Neurosci 30:42104220.

Griffen TC, Maffei A (2014) GABAergic synapses: their plasticity and role in sensory cortex. Front Cell Neurosci 8:91.

Guest H, Munro KJ, Prendergast G, Howe S, Plack CJ (2017) Tinnitus with a normal audiogram: relation to noise exposure but no evidence for cochlear synaptopathy. Hear Res 344:265-274.

Heil P, Neubauer H, Brown M, Irvine DR (2008) Towards a unifying basis of auditory thresholds: distributions of the first-spike latencies of auditorynerve fibers. Hear Res 238:25-38.

Henry JA, Roberts LE, Caspary DM, Theodoroff SM, Salvi RJ (2014) Underlying mechanisms of tinnitus: review and clinical implications. J Am Acad Audiol 25:5-22.

Hickox AE, Liberman MC (2014) Is noise-induced cochlear neuropathy key to the generation of hyperacusis or tinnitus? J Neurophysiol 111:552564 .

Hofmeier B, Wolpert S, Aldamer ES, Walter M, Thiericke J, Braun C, Zelle D, Ruttiger L, Klose U, Knipper M (2018) Reduced sound-evoked and resting-state BOLD fMRI connectivity in tinnitus. Neuroimage Clin 20:637-649. 
Hong EJ, McCord AE, Greenberg ME (2008) A biological function for the neuronal activity-dependent component of Bdnf transcription in the development of cortical inhibition. Neuron 60:610-624.

Hsieh TH, Lee HH, Hameed MQ, Pascual-Leone A, Hensch TK, Rotenberg A (2017) Trajectory of parvalbumin cell impairment and loss of cortical inhibition in traumatic brain injury. Cereb Cortex 27:5509-5524.

Hu H, Gan J, Jonas P (2014) Interneurons. Fast-spiking, parvalbumin ${ }^{+}$ GABAergic interneurons: from cellular design to microcircuit function. Science 345:1255263.

$\mathrm{Hu} \mathrm{H}$, Roth FC, Vandael D, Jonas P (2018) Complementary tuning of $\mathrm{Na}(+)$ and $\mathrm{K}(+)$ channel gating underlies fast and energy-efficient action potentials in GABAergic interneuron axons. Neuron 98:156-165.e156.

Hullfish J, Sedley W, Vanneste S (2019) Prediction and perception: insights for (and from) tinnitus. Neurosci Biobehav Rev 102:1-12.

Irvine DR (2018a) Plasticity in the auditory system. Hear Res 362:61-73.

Irvine DR (2018b) Auditory perceptual learning and changes in the conceptualization of auditory cortex. Hear Res 366:3-16.

Itami C, Kimura F, Nakamura S (2007) Brain-derived neurotrophic factor regulates the maturation of layer 4 fast-spiking cells after the second postnatal week in the developing barrel cortex. J Neurosci 27:2241-2252.

Jastreboff PJ, Gray WC, Gold SL (1996) Neurophysiological approach to tinnitus patients. Am J Otol 17:236-240.

Kalappa BI, Brozoski TJ, Turner JG, Caspary DM (2014) Single unit hyperactivity and bursting in the auditory thalamus of awake rats directly correlates with behavioural evidence of tinnitus. J Physiol 592:5065-5078.

Kandler K, Friauf E (1995) Development of glycinergic and glutamatergic synaptic transmission in the auditory brainstem of perinatal rats. J Neurosci 15:6890-6904.

Kann O (2016) The interneuron energy hypothesis: implications for brain disease. Neurobiol Dis 90:75-85.

Khirug S, Ahmad F, Puskarjov M, Afzalov R, Kaila K, Blaesse P (2010) A single seizure episode leads to rapid functional activation of KCC2 in the neonatal rat hippocampus. J Neurosci 30:12028-12035.

Kilgard MP, Pandya PK, Engineer ND, Moucha R (2002) Cortical network reorganization guided by sensory input features. Biol Cybern 87:333-343.

Kim H, ährlund-Richter S, Wang X, Deisseroth K, Carlén M (2016) Prefrontal parvalbumin neurons in control of attention. Cell 164:208218.

Kimura F, Itami C (2019) A hypothetical model concerning how spike-timing-dependent plasticity contributes to neural circuit formation and initiation of the critical period in barrel cortex. J Neurosci 39:3784-3791.

Knipper M, Van Dijk P, Nunes I, Rüttiger L, Zimmermann U (2013) Advances in the neurobiology of hearing disorders: recent developments regarding the basis of tinnitus and hyperacusis. Prog Neurobiol 111:1733.

Knopke S, Szczepek AJ, Haussler SM, Grabel S, Olze H (2017) Cochlear implantation of bilaterally deafened patients with tinnitus induces sustained decrease of tinnitus-related distress. Front Neurol 8:158.

Koops EA, Lanting CP, Renken RJ, Van Dijk P (2020) Cortical tonotopic maps changes in humans are larger in hearing loss than in additional tinnitus. J Neurosci 40:3178-3185.

Kral A, O’Donoghue GM (2010) Profound deafness in childhood. N Engl J Med 363:1438-1450.

Kraus N, White-Schwoch T (2015) Unraveling the biology of auditory learning: a cognitive-sensorimotor-reward framework. Trends Cogn Sci 19:642-654

Krauss P, Tziridis K, Metzner C, Schilling A, Hoppe U, Schulze H (2016) Stochastic resonance controlled upregulation of internal noise after hearing loss as a putative cause of tinnitus-related neuronal hyperactivity. Front Neurosci 10:597.

Krauss P, Metzner C, Schilling A, Schutz C, Tziridis K, Fabry B, Schulze H (2017) Adaptive stochastic resonance for unknown and variable input signals. Sci Rep 7:2450.

Langers DR, de Kleine E, van Dijk P (2012) Tinnitus does not require macroscopic tonotopic map reorganization. Front Syst Neurosci 6:2.

Lanting CP, de Kleine E, Langers DR, van Dijk P (2014) Unilateral tinnitus: changes in connectivity and response lateralization measured with FMRI. PLoS One 9:e110704.

Leaver AM, Turesky TK, Seydell-Greenwald A, Morgan S, Kim HJ, Rauschecker JP (2016) Intrinsic network activity in tinnitus investigated using functional MRI. Hum Brain Mapp 37:2717-2735.
Lee HH, Deeb TZ, Walker JA, Davies PA, Moss SJ (2011) NMDA receptor activity downregulates $\mathrm{KCC} 2$ resulting in depolarizing GABAA receptormediated currents. Nat Neurosci 14:736-743.

Lee SY, Nam DW, Koo JW, De Ridder D, Vanneste S, Song JJ (2017) No auditory experience, no tinnitus: lessons from subjects with congenital- and acquired single-sided deafness. Hear Res 354:9-15.

Lehmann K, Steinecke A, Bolz J (2012) GABA through the ages: regulation of cortical function and plasticity by inhibitory interneurons. Neural Plast 2012:892784.

Leutgeb JK, Leutgeb S, Moser MB, Moser EI (2007) Pattern separation in the dentate gyrus and CA3 of the hippocampus. Science 315:961-966.

Levy SC, Freed DJ, Nilsson M, Moore BC, Puria S (2015) Extended high-frequency bandwidth improves speech reception in the presence of spatially separated masking speech. Ear Hear 36:e214-e224.

Li C, Kuhlmey M, Kim AH (2019) Electroacoustic stimulation. Otolaryngol Clin North Am 52:311-322.

Lobarinas E, Hayes SH, Allman BL (2013) The gap-startle paradigm for tinnitus screening in animal models: limitations and optimization. Hear Res 295:150-160.

Lodge DJ, Behrens MM, Grace AA (2009) A loss of parvalbumin-containing interneurons is associated with diminished oscillatory activity in an animal model of schizophrenia. J Neurosci 29:2344-2354.

Lohmann C, Friauf E (1996) Distribution of the calcium-binding proteins parvalbumin and calretinin in the auditory brainstem of adult and developing rats. J Comp Neurol 367:90-109.

Malmierca MS, Sanchez-Vives MV, Escera C, Bendixen A (2014) Neuronal adaptation, novelty detection and regularity encoding in audition. Front Syst Neurosci 8:111.

Mamashli F, Khan S, Bharadwaj H, Michmizos K, Ganesan S, Garel KA, Ali Hashmi J, Herbert MR, Hamalainen M, Kenet T (2017) Auditory processing in noise is associated with complex patterns of disrupted functional connectivity in autism spectrum disorder. Autism Res 10:631-647.

Marin O, Rubenstein JL (2001) A long, remarkable journey: tangential migration in the telencephalon. Nat Rev Neurosci 2:780-790.

Matt L, Eckert P, Panford-Walsh R, Geisler HS, Bausch AE, Manthey M, Muller NI, Harasztosi C, Rohbock K, Ruth P, Friauf E, Ott T, Zimmermann U, Ruttiger L, Schimmang T, Knipper M, Singer W (2018) Visualizing BDNF transcript usage during sound-induced memory linked plasticity. Front Mol Neurosci 11:260.

Mazurek B, Szczepek AJ, Bruggemann P (2017) Tinnitus: clinical symptoms and therapy. Laryngorhinootologie 96:47-59.

McAlpine D, Martin RL, Mossop JE, Moore DR (1997) Response properties of neurons in the inferior colliculus of the monaurally deafened ferret to acoustic stimulation of the intact ear. J Neurophysiol 78:767-779.

McKlveen JM, Morano RL, Fitzgerald M, Zoubovsky S, Cassella SN, Scheimann JR, Ghosal S, Mahbod P, Packard BA, Myers B, Baccei ML, Herman JP (2016) Chronic stress increases prefrontal inhibition: a mechanism for stress-induced prefrontal dysfunction. Biol Psychiatry 80:754764.

Meddis R (2006) Auditory-nerve first-spike latency and auditory absolute threshold: a computer model. J Acoust Soc Am 119:406-417.

Melcher JR, Levine RA, Bergevin C, Norris B (2009) The auditory midbrain of people with tinnitus: abnormal sound-evoked activity revisited. Hear Res 257:63-74.

Merchan-Perez A, Liberman MC (1996) Ultrastructural differences among afferent synapses on cochlear hair cells: correlations with spontaneous discharge rate. J Comp Neurol 371:208-221.

Mertens G, Van Rompaey V, Van de Heyning P (2018) Electric-acoustic stimulation suppresses tinnitus in a subject with high-frequency singlesided deafness. Cochlear Implants Int 19:292- 295.

Milbrandt JC, Holder TM, Wilson MC, Salvi RJ, Caspary DM (2000) GAD levels and muscimol binding in rat inferior colliculus following acoustic trauma. Hear Res 147:251-260.

Miller EK, Buschman TJ (2013) Cortical circuits for the control of attention. Curr Opin Neurobiol 23:216-222.

Milloy V, Fournier P, Benoit D, Norena A, Koravand A (2017) Auditory brainstem responses in tinnitus: a review of who, how, and what? Front Aging Neurosci 9:237.

Möhrle D, Hofmeier B, Amend M, Wolpert S, Ni K, Bing D, Klose U, Pichler B, Knipper M, Rüttiger L (2019) Enhanced central neural gain compensates acoustic trauma-induced cochlear impairment, but unlikely correlates with tinnitus and hyperacusis. Neuroscience 407:146-169. 
Moller AR, Salvi R, De Ridder D, Kleinjung T, Vanneste S (2015) Pathology of tinnitus and hyperacusis: clinical implications. Biomed Res Int 2015:608437.

Mossop JE, Wilson MJ, Caspary DM, Moore DR (2000) Down-regulation of inhibition following unilateral deafening. Hear Res 147:183-187.

Muhlau M, Rauschecker JP, Oestreicher E, Gaser C, Rottinger M, Wohlschlager AM, Simon F, Etgen T, Conrad B, Sander D (2006) Structural brain changes in tinnitus. Cereb Cortex 16:1283-1288.

Müller M, Klinke R, Arnold W, Oestreicher E (2003) Auditory nerve fibre responses to salicylate revisited. Hear Res 183:37-43.

Nardou R, Yamamoto S, Chazal G, Bhar A, Ferrand N, Dulac O, Ben-Ari Y, Khalilov I (2011) Neuronal chloride accumulation and excitatory GABA underlie aggravation of neonatal epileptiform activities by phenobarbital. Brain 134:987-1002.

Neville H, Bavelier D (2002) Human brain plasticity: evidence from sensory deprivation and altered language experience. Prog Brain Res 138:177188.

Norena AJ (2011) An integrative model of tinnitus based on a central gain controlling neural sensitivity. Neurosci Biobehav Rev 35:1089-1109.

Norena AJ, Farley BJ (2013) Tinnitus-related neural activity: theories of generation, propagation, and centralization. Hear Res 295:161-171.

Nunez A, Malmierca E (2007) Corticofugal modulation of sensory information. Adv Anat Embryol Cell Biol 187:1.

Obleser J, Wise RJ, Dresner MA, Scott SK (2007) Functional integration across brain regions improves speech perception under adverse listening conditions. J Neurosci 27:2283-2289.

Ortiz-Mantilla S, Hamalainen JA, Realpe-Bonilla T, Benasich AA (2016) Oscillatory dynamics underlying perceptual narrowing of native phoneme mapping from 6 to 12 months of age. J Neurosci 36:12095-12105.

Ortmann M, Muller N, Schlee W, Weisz N (2011) Rapid increases of gamma power in the auditory cortex following noise trauma in humans. Eur J Neurosci 33:568-575.

Pillsbury HC, 3rd, Dillon MT, Buchman CA, Staecker H, Prentiss SM, Ruckenstein MJ, Bigelow DC, Telischi FF, Martinez DM, Runge CL, Friedland DR, Blevins NH, Larky JB, Alexiades G, Kaylie DM, Roland PS, Miyamoto RT, Backous DD, Warren FM, El-Kashlan HK, et al. (2018) Multicenter US clinical trial with an electric-acoustic stimulation (EAS) system in adults: final outcomes. Otol Neurotol 39:299-305.

Pouille F, Scanziani M (2001) Enforcement of temporal fidelity in pyramidal cells by somatic feed-forward inhibition. Science 293:1159-1163.

Punte AK, De Ridder D, Van de Heyning P (2013) On the necessity of full length electrical cochlear stimulation to suppress severe tinnitus in single-sided deafness. Hear Res 295:24-29.

Rajan G, Tavora-Vieira D, Baumgartner WD, Godey B, Müller J, O’Driscoll M, Skarzynski H, Skarzynski P, Usami SI, Adunka O, Agrawal S, Bruce I, De Bodt M, Caversaccio M, Pilsbury H, Gavilán J, Hagen R, Hagr A, Kameswaran M, Karltorp E, et al. (2018) Hearing preservation cochlear implantation in children: the HEARRING Group consensus and practice guide. Cochlear Implants Int 19:1-13.

Ramakers GG, van Zon A, Stegeman I, Grolman W (2015) The effect of cochlear implantation on tinnitus in patients with bilateral hearing loss: a systematic review. Laryngoscope 125:2584-2592.

Rauschecker JP, May ES, Maudoux A, Ploner M (2015) Frontostriatal gating of tinnitus and chronic pain. Trends Cogn Sci 19:567-578.

Rich MM, Wenner P (2007) Sensing and expressing homeostatic synaptic plasticity. Trends Neurosci 30:119-125.

Roberts LE (2018) Neural plasticity and its initiating conditions in tinnitus. HNO 66:172-178.

Roberts LE, Eggermont JJ, Caspary DM, Shore SE, Melcher JR, Kaltenbach JA (2010) Ringing ears: the neuroscience of tinnitus. J Neurosci 30:14972-14979.

Roberts LE, Salvi R (2019) Overview: hearing loss, tinnitus, hyperacusis, and the role of central gain. Neuroscience 407:1-7.

Rosing SN, Schmidt JH, Wedderkopp N, Baguley DM (2016) Prevalence of tinnitus and hyperacusis in children and adolescents: a systematic review. BMJ Open 6:e010596.

Rossignol E, Kruglikov I, van den Maagdenberg AM, Rudy B, Fishell G (2013) CaV 2.1 ablation in cortical interneurons selectively impairs fastspiking basket cells and causes generalized seizures. Ann Neurol 74:209222.

Rüttiger L, Singer W, Panford-Walsh R, Matsumoto M, Lee SC, Zuccotti A, Zimmermann U, Jaumann M, Rohbock K, Xiong H, Knipper M (2013)
The reduced cochlear output and the failure to adapt the central auditory response causes tinnitus in noise exposed rats. PLoS One 8:e57247.

Schaette R, Kempter R (2012) Computational models of neurophysiological correlates of tinnitus. Front Syst Neurosci 6:34.

Schaette R, McAlpine D (2011) Tinnitus with a normal audiogram: physiological evidence for hidden hearing loss and computational model. J Neurosci 31:13452-13457.

Schecklmann M, Vielsmeier V, Steffens T, Landgrebe M, Langguth B, Kleinjung T (2012) Relationship between audiometric slope and tinnitus pitch in tinnitus patients: insights into the mechanisms of tinnitus generation. PLoS One 7:e34878.

Schmidt SA, Carpenter-Thompson J, Husain FT (2017) Connectivity of precuneus to the default mode and dorsal attention networks: a possible invariant marker of long-term tinnitus. Neuroimage Clin 16:196-204.

Schonwiesner M, Novitski N, Pakarinen S, Carlson S, Tervaniemi M, Naatanen R (2007) Heschl's gyrus, posterior superior temporal gyrus, and mid-ventrolateral prefrontal cortex have different roles in the detection of acoustic changes. J Neurophysiol 97:2075-2082.

Searchfield GD (2014) Tinnitus what and where: an ecological framework. Front Neurol 5:271.

Searchfield GD, Kaur M, Martin WH (2010) Hearing aids as an adjunct to counseling: tinnitus patients who choose amplification do better than those that don't. Int J Audiol 49:574-579.

Sedley W (2019) Tinnitus: does gain explain? Neuroscience 407:213-228.

Sedley W, Friston KJ, Gander PE, Kumar S, Griffiths TD (2016) An integrative tinnitus model based on sensory precision. Trends Neurosci 39:799812.

Shargorodsky J, Curhan GC, Farwell WR (2010) Prevalence and characteristics of tinnitus among US adults. Am J Med 123:711-718.

Sharma M, Bist SS, Kumar S (2016) Age-related maturation of wave V latency of auditory brainstem response in children. J Audiol Otol 20:97101.

Shekhawat GS, Searchfield GD, Stinear CM (2013) Role of hearing AIDS in tinnitus intervention: a scoping review. J Am Acad Audiol 24:747-762.

Shibata S, Kakazu Y, Okabe A, Fukuda A, Nabekura J (2004) Experience-dependent changes in intracellular $\mathrm{Cl}$ - regulation in developing auditory neurons. Neurosci Res 48:211-220.

Shih HC, Kuan YH, Shyu BC (2017) Targeting brain-derived neurotrophic factor in the medial thalamus for the treatment of central poststroke pain in a rodent model. Pain 158:1302-1313.

Shore SE, Roberts LE, Langguth B (2016) Maladaptive plasticity in tinnitus: triggers, mechanisms and treatment. Nat Rev Neurol 12:150-160.

Siegle JH, Pritchett DL, Moore CI (2014) Gamma-range synchronization of fast-spiking interneurons can enhance detection of tactile stimuli. Nat Neurosci 17:1371-1379.

Singer W, Kasini K, Manthey M, Eckert P, Armbruster P, Vogt MA, Jaumann M, Dotta M, Yamahara K, Harasztosi C, Zimmermann U, Knipper M, Ruttiger L (2018) The glucocorticoid antagonist mifepristone attenuates sound-induced long-term deficits in auditory nerve response and central auditory processing in female rats. FASEB J 32:3005-3019.

Singer W, Zuccotti A, Jaumann M, Lee SC, Panford-Walsh R, Xiong H, Zimmermann U, Franz C, Geisler HS, Köpschall I, Rohbock K, Varakina K, Verpoorten S, Reinbothe T, Schimmang T, Rüttiger L, Knipper M (2013) Noise-induced inner hair cell ribbon loss disturbs central arc mobilization: a novel molecular paradigm for understanding tinnitus. Mol Neurobiol 47:261-279.

Sohal VS, Zhang F, Yizhar O, Deisseroth K (2009) Parvalbumin neurons and gamma rhythms enhance cortical circuit performance. Nature 459:698702 .

Sowell ER, Delis D, Stiles J, Jernigan TL (2001) Improved memory functioning and frontal lobe maturation between childhood and adolescence: a structural MRI study. J Int Neuropsychol Soc 7:312-322.

Sullivan RM, Gratton A (2002) Prefrontal cortical regulation of hypothalamic-pituitary-adrenal function in the rat and implications for psychopathology: side matters. Psychoneuroendocrinology 27:99-114.

Tighilet B, Dutheil S, Siponen MI, Norena AJ (2016) Reactive neurogenesis and down-regulation of the potassium-chloride cotransporter KCC2 in the cochlear nuclei after cochlear deafferentation. Front Pharmacol 7:281.

Tillein J, Hubka P, Kral A (2016) Monaural congenital deafness affects aural dominance and degrades binaural processing. Cereb Cortex 26:17621777 . 
Tsukada K, Nishio S, Usami S, Deafness Gene Study Consortium (2010) A large cohort study of GJB2 mutations in Japanese hearing loss patients. Clin Genet 78:464-470.

Turrigiano G (2012) Homeostatic synaptic plasticity: local and global mechanisms for stabilizing neuronal function. Cold Spring Harb Perspect Biol 4:a005736

Tyler R, Coelho C, Tao P, Ji H, Noble W, Gehringer A, Gogel S (2008a) Identifying tinnitus subgroups with cluster analysis. Am J Audiol 17: S176-S184.

Tyler RS, Rubinstein J, Pan T, Chang SA, Gogel SA, Gehringer A, Coelho C (2008b) Electrical stimulation of the cochlea to reduce tinnitus. Semin Hear 29:326-332.

Tziridis K, Ahlf S, Jeschke M, Happel MF, Ohl FW, Schulze H (2015) Noise trauma induced neural plasticity throughout the auditory system of mongolian gerbils: differences between tinnitus developing and non-developing animals. Front Neurol 6:22.

Van de Heyning P, Vermeire K, Diebl M, Nopp P, Anderson I, De Ridder D (2008) Incapacitating unilateral tinnitus in single-sided deafness treated by cochlear implantation. Ann Otol Rhinol Laryngol 117:645-652.

Vanneste S, De Ridder D (2012) The auditory and non-auditory brain areas involved in tinnitus: an emergent property of multiple parallel overlapping subnetworks. Front Syst Neurosci 6:31.

Vanneste S, To WT, De Ridder D (2019) Tinnitus and neuropathic pain share a common neural substrate in the form of specific brain connectivity and microstate profiles. Prog Neuropsychopharmacol Biol Psychiatry 88:388-400

Viho EM, Buurstede JC, Mahfouz A, Koorneef LL, van Weert L, Houtman R, Hunt HJ, Kroon J, Meijer OC (2019) Corticosteroid action in the brain: the potential of selective receptor modulation. Neuroendocrinology 109:266-276.

Wardle RA, Poo MM (2003) Brain-derived neurotrophic factor modulation of GABAergic synapses by postsynaptic regulation of chloride transport. J Neurosci 23:8722-8732.

Weinberger NM (2015) New perspectives on the auditory cortex: learning and memory. Handb Clin Neurol 129:117-147.

Weisz N, Hartmann T, Dohrmann K, Schlee W, Norena A (2006) High-frequency tinnitus without hearing loss does not mean absence of deafferentation. Hear Res 222:108-114.

Weisz N, Muller S, Schlee W, Dohrmann K, Hartmann T, Elbert T (2007) The neural code of auditory phantom perception. J Neurosci 27:1479-1484.

Wilson BS (2017) The modern cochlear implant: a triumph of biomedical engineering and the first substantial restoration of human sense using a medical intervention. IEEE Pulse 8:29-32.

Wittekindt A, Kaiser J, Abel C (2014) Attentional modulation of the inner ear: a combined otoacoustic emission and EEG study. J Neurosci 34:9995-10002.

Xu H, Kotak VC, Sanes DH (2010) Normal hearing is required for the emergence of long-lasting inhibitory potentiation in cortex. J Neurosci 30:331-341.

Yates GK (1991) Auditory-nerve spontaneous rates vary predictably with threshold. Hear Res 57:57-62.

Youssofzadeh V, Vannest J, Kadis DS (2018) fMRI connectivity of expressive language in young children and adolescents. Hum Brain Mapp 39:35863596.

Zeng FG (2013) An active loudness model suggesting tinnitus as increased central noise and hyperacusis as increased nonlinear gain. Hear Res 295:172-179. 